http://dx.doi.org/10.12795/PH.1991.v06.i01.05

\title{
A través del cuerpo. Metonimia y ensoñación
}

Mª Concepción Pérez y Pérez

El objeto del presente trabajo se centra en una reflexión en torno al fetichismo corporal en la escritura de Bernanos. Bajo un título algo vago, pretendo hacer hincapié en la función del cuerpo como punto de partida de la ensoñación de la escritura, desde una proyección metonímica sobre un elemento corporal u objeto asociado al cuerpo. Para ello, desarrollaré un planteamiento de carácter temático, en el sentido que la crítica de este nombre confiere a dicho término, a partir de la configuración de la imagen desde la inmanencia textual, como un sistema semiótico de transposición de realidad. No entraré, por tanto, en consideraciones de carácter psicoanalítico o antropológico que pudieran trascender el espacio del texto, centrando de manera exclusiva mi objetivo en el interior de su ámbito sin partir de prefijación alguna.

Si bien podemos establecer una serie de constantes en torno al fetichismo corporal en el microcosmos narrativo de la escritura bernanosiana, su focalización se centra de manera preferente en un aspecto específico en cada obra. Por ello, realizaré una breve prospección sobre tres novelas, situadas al principio y en la plenitud y fin de su trayectoria como novelista: Bajo el sol de Satanás (Sous le soleil de Satan), La Nueva Historia de Mouchette (Nouvelle Histoire de Mouchette) y El Señor Ouine (Monsieur Ouine).

Debido al encadenamiento que desde el punto de visa temático estructura el imaginario del autor, y para una mayor claridad en la exposición, partiré de la hoja central del tríptico -La Nueva Historia de Mouchette - para terminar con la novela que inaugura la producción de la escritura de Bernanos. El movimiento que voy a describir irá, por tanto, del fetichismo de la mano al de la nariz para culminar con la fijación en el zapato y la ensoñación de le existencia que en función de ella se lleva a cabo.

\section{Presencia y significación de las manos}

La presencia de las manos genera gestos puntuales en las novelas de Bernanos, como rápidos flashes visuales donde apenas se detiene la mirada. Sin embargo, en $L a$ 
nueva Historia de Mouchette, la fijación en la mano adquiere una especial importancia y peso específico, accediendo a un significado múltiple. De esta manera, algo tan intangible y etéreo como el propio canto es accesible al tacto: Mouchette, en lo que constituye una de las escenas centrales del texto, «escuchaba subir su canto con humilde fervor, refrescaba su cuerpo y su alma, hubiera querido mojar sus manos en él», ${ }^{1}$ según observa el narrador. Y el contacto de la mano, en la dialéctica que se establece con el otro, es esencial en esta novela, más que en ninguna otra de Bernanos. Fijémonos, por tanto, en la serie de asociaciones que a partir de la mano se establecen en el texto.

La primera de ellas, y punto de partida, viene configurada por la relación manomirada: contemplando absorta a su amante dormido, el narrador comenta cómo el rostro de éste «cabía tan fácilmente en la mirada de Mouchette como el mango de su viejo cuchillo en la palma de su mano» ${ }^{2}$. Y en función de la misma asociación, las manos del señor Ouine, en la novela de igual nombre, están hinchadas por el mismo líquido seroso que destilan incansablemente sus párpados ${ }^{3}$.

La especial fijación de Mouchette en las manos radica, precisamente, en ser un sustituto de la mirada, llegando, como tal, a superar a aquella:

«Siempre intimidada por la mirada [Mouchette] había descubierto la prodigiosa facultad de expresión de las manos humanas, mil veces más reveladoras que los ojos, pues apenas son hábiles en mentir, se dejan sorprender a cada momento ocupadas de mil cuidados materiales, mientras que la mirada, centinela infatigable, vela en las almenas de los párpados...»"

Y el autor establece a continuación toda una tipología de manos, desde las de la maestra -pequeñas como la mezquindad del ser al que pertenecen- a las largas manos, «rezagadas en las puertas de los coches», de las bellas muchachas risueñas que vuelven cada verano y conforman, en la mente de Mouchette, un espacio ideal de pureza.

La carga que como imagen visual adquiere la mano, va a establecer, por otra parte, un estrecho vínculo con la memoria. Y ello hasta tal punto que, a través del contacto por la memoria, la mano adquiere una presencia más viva que en su propia realidad física, y es más tibia y perfumada en el tiempo del recuerdo que en el tiempo real ${ }^{5}$.

Pero, además, ella lleva escrita la historia personal y transpersonal. De esta manera, Mouchette, mirándosela, recuerda las veces que la maestra ha mostrado ante

${ }^{1}$ G. Bernanos (1988), Oeuvres romanesques, Nouvelle Histoire de Mouchette, París, Gallimard, Biblioteca de La Pléiade, p. 1292. El canto es especialmente relevante desde el punto de vista simbólico en este texto: Mouchette se niega a él, o lo distorsiona, cuando le es exigido por la maestra. Sin embargo, el canto irrumpe, espontáneo, como elocuencia íntima y efusión del ser, como el don de uno mismo, en el descubrimiento del amor. La traducción de éste y de todos los textos citados es máa.

${ }^{2}$ Ibid., p. 1288.

${ }^{3}$ El señor Ouine es un ser que se diluye, en el más puro sentido del término, dentro de un proceso de desintegración existencial.

${ }^{4}$ Nouvelle Histoire de Mouchette, p. 1341.

${ }^{5} \mathrm{La}$ consistencia de realidad que la memoria procura es tal, que el recuerdo de la caricia de la desconocida provoca en Mouchette un inmediato deseo de besar su mano. 
toda la clase esa mano sucia, «dispensadora de gérmenes». Detonante del recuerdo, en la mano está inserta, además, la memoria de la herencia detestada. Así, y en primer lugar, las manos de la madre son evocadas por su carácter nefasto, pues pertenecen a la raza maldita de las manos nacidas tan sólo para trabajar. Pero, sobre todo, es especialmente significativa la presencia de la mano odiada del padre, a partir de una transposición sobre la de Mouchette, por una deformación en el pulgar que la hace semejante al dedo casi monstruoso del padre. «Semejante mano, observa el autor, es de esas que llevan el sino de la desgracia» ${ }^{6}$.

No es entonces de extrañar que sea la contemplación de esta parte del cuerpo el elemento que provoque directamente la idea del suicidio en la niña, ya que, metonimia del ser, la mano es lo que muere primero:

«Esa mano morena con las uñas todavía llenas de tierra estaba ahí, ante sus ojos, ya arrugada, ya marchita, y sin embargo todavía tan pueril sobre la frágil muñeca. Y, por un instante, Mouchette la vio muerta en efecto, tal cual, en la tierra negra. Se puso a odiar esa mano como si no le húbiera pertenecido, como una cosa extraña y detestable. En ese instante, y por ese motivo fútil, la piedad que empezaba a sentir para consigo misma se disipó de golpe»?

La asociación mano-memoria conduce, pues, a la asociación mano-muerte. Esta última, entonces, no es sino el momento privilegiado de recuperación de la memoria, como tiempo que los subsume todos, como momento culmen de definición o negación del ser ${ }^{8}$.

\section{La nariz como receptáculo de la memoria}

Desde otra fijación fetichista, la nariz va a cubrir una función muy parecida a la de las manos en esa extraña y original creación de Bernanos que es Monsieur Ouine. Uno de los personajes más curiosos del texto, el alcalde de Fenouille, se caracteriza por la peculiaridad de una nariz que el narrador describe «brillante por el herpes, con su red de venillas azules, su redondez elástica, su excesiva movilidad».

Se trata de una nariz que, como observa el propio autor, «en medio de esa cara gastada estalla con una vida espantosa, burlona» ${ }^{9}$. Las muchachas, divertidas, ríen al tocarla, sintiendo latir su corazón, «como si tuvieras en la mano un auténtico animal», mientras la autonomía que alcanza este apéndice monstruoso con vida propia aterroriza a la alcaldesa.

\footnotetext{
${ }^{6}$ Ibid., p. 1340.

${ }^{7}$ Ibid., p. 1339.

${ }^{8}$ Por ello, la presencia de la agonía aparece como una gran constante en las novelas de Bernanos. «Verse morir» es la gran obsesión de los personajes que la pueblan, y el gran fracaso del señor Ouine.

${ }^{9} \mathrm{G}$. Bernanos, Oeuvres romanesques (cit.), Monsieur Ouine, p. 1393.
} 
Para el alcalde, sin embargo, constituye un motivo de orgullo, «mi grisgris», confiesa refiriéndose a su carga de amuleto erótico infalible.

El drama da comienzo en el momento en que, pasada la barrera de los sesenta, el alcalde toma conciencia de la diferencia, capital y nefasta, que su peculiaridad le otorga. La duda empieza a anidar y resquebrajar la conciencia desde el momento en que descubre cómo, a través de su nariz, no ha hecho sino llevar a cabo una horrible absorción, de la juventud primero, y de la vejez, que como aquella tiene su olor, después. La nariz se convierte entonces en el receptáculo de la memoria:

«Es verdad que ha aspirado, olfateado, husmeado más que nadie, que ha poseído su juventud por la nariz, y la vejez incipiente también tiene su olor... Su verdadera memoria está ahí, entre los dos ojos, en el fondo de esas criptas oscuras» ${ }^{10}$.

Podemos comprobar, además, que la asociación con la muerte es inmediata a partir del empleo metafórico de la cripta. De hecho, lo que el alcalde de Fenouille hace con su portentosa y obscena nariz es olfatear la muerte. Si para el doctor Malépine se trata de un simple caso de perversión sexual, para Bernanos, a quien el psicoanálisis no satisfacf́a, lo que subyace es la nostalgia de la pureza desde una perspectiva metafísica, la tensión al absoluto. Para arrancarse la memoria de su absorción olfativa, de una nariz que filtra el mundo a través de invisibles cilios, el alcalde adquiere una auténtica manía lavatoria, no tanto para purificarse como para alcanzar un estado de amnesia, la noche en blanco sin sueños.

$Y$ es que la absorción finalmente se reabsorbe en vacío, del mismo modo que el Señor Ouine, gourmand de la existencia, se desintegra por dentro, y en uno y otro personaje, la primera marca de la desintegración será discursiva ${ }^{11}$.

$\mathrm{Y}$ es así como dos personajes en principio dispares participan de una cierta similitud ante el planteamiento de la existencia, cuya base el tedio. La similitud genera una transposición que se plasma finalmente en imagen, de tal manera que, tras la muerte del Señor Ouine, el rostro del cadáver sufre un proceso de endurecimiento, como una moneda o una arcilla sólida, donde la nariz es lo único vivo:

«Esta masa adquiere poco a poco el color de la arcilla, parece endurecerse con el aire, hasta el punto de que la claridad de la lámpara se niega a acariciar sus contornos. Tan sólo la nariz, que alarga desmesuradamente la cuenca de las órbitas, el hundimiento de los músculos del rostro, permanece viva con una vida ya sin causa y sin objeto, como un animalillo maligno» ${ }^{12}$.

Tal es el punto final de la novela, centrándose la focalización del descriptor en la imagen de la nariz que, prodigiosamente alargada, adquiere un volumen, consistencia y vida propia que la hacen equiparable a la del alcalde: la imagen última del texto,

\footnotetext{
${ }^{10}$ Tbid., p. 1394.

${ }^{11} \mathrm{La}$ elección del nombre es significativa al respecto: el señor Ouine es el señor Sí-no.

${ }^{12}$ Monsieur Ouine, p. 1562.
} 
construida sobre la fijación en el muerto, destaca la misteriosa vida de una nariz que abre espacios de intranquilidad, como un animalillo oscuro.

\section{Del zapato a la carretera como metáfora existencial}

Testigo mudo de una ausencia, o significante del modo de estar de una presencia, el zapato metonimiza, resumiéndola, la esencia entera del ser. La carga fetichista que dicho objeto recibe es tal, que además de la función simbólica cubierta, en la estructura narrativa puede llegar a desempeñar una función actancial. De esta manera, un texto como la Nueva Historia de Mouchette construye toda su dinámica a partir del tema del zapato perdido, muy distinto, sin embargo, de aquel que perdiera Cenicienta. Los zuecos son el elemento asociado metonímicamente a la adolescente protagonista de la historia, cuya dinámica fatal se desencadena a partir del preciso instante en que pierde uno de ellos, literalmente tragado -precisa el narrador- por el lengüetazo de las fauces de la tierra.

Tiene lugarentonces el encuentro entre la niña y el cazador furtivo, inmediatamente reconocido por «su marcha prudente de animal nocturno». Sus gruesas botas «desprenden un fuerte olor a grasa y a mantillo», con toda la carga erótico-viril que ello conlleva. A partir de este momento, una doble polaridad referencial se instaura en el zueco, aplicable, por una parte, al padre, y, por otra, al cazador ensoñado como posible amante. La referencia al padre, por parte del amante, es inmediata ( $\$$ Si vuelves a casa de tu padre sin tus dos zuecos, cuidado con la azotaina», le dice a la niña al encontrarla en el bosque ${ }^{13}$ ). De hecho, lo que se produce, en realidad, es una superposición entre ambas figuras, manteniéndose de manera constante, a partir del momento del encuentro, a lo largo de todo el texto. Y, tras el fracaso definitivo del sueño de amor, es la imagen del padre, tematizada en la contemplación de la mano, según veíamos más arriba, el detonante directo del suicidio.

En la dinámica existencial de Mouchette, la búsqueda del zueco perdido se plantea como el inicio de una relación de fraternidad y complicidad entre el cazador furtivo y la niña salvaje, seres marginales los dos. «Tú no eres una chica como las otras, tú eres una buena chica. Me voy a buscar tu zapato» ${ }^{14}$, dice inesperadamente Arsène al contemplar en Mouchette una imagen del doble semejante a si mismo. Pero el zapato es finalmente encontrado en las aguas torrenciales de las lluvias, que arrastran animales muertos, los mismos que llenan el zurrón del cazador, con el pelaje pegajoso de agua y sangre. Mal signo, que se traduce inmediatamente en la mirada densa del furtivo. El carácter de premonición nefasta (verdadera prolepsis narrativa) se contempla con la focalización del descriptor sobre la blanca mano de Arsène -más blancas que las de las gentes del pueblo, las manos de Arsène hacen de él un ser diferente e ideal en la mente

\footnotetext{
${ }^{13}$ Nouvelle Histoire de Mouchette, p. 1273.

${ }^{14}$ Ibid., p. 1278.
} 
de Mouchette- deformada por una extraña herida, y posteriormente cubierta de sangre ${ }^{15}$. De esta manera, la relación de complicidad fraternal se ve truncada con el acto de la violación, y el sueño de amor de Mouchette definitivamente roto: al final de la noche delirante, la niña volverá a casa con los zuecos llenos de barro y hojas podridas ${ }^{16}$.

En ellos toma cuerpo la dimensión trágica y grotesca de la aventura amorosa: «El cuero de sus zuecos ha tomado el color de la herrumbre y, al secarse, se han encogido de una manera grotesca», precisa el narrador ${ }^{17}$. El zapato se convierte entonces en metáfora de la propia existencia.

Se inserta entonces en el zapato una dimensión temporal irremediablemente asociada a la muerte. Los zuecos toman el color de la herrumbre, como los imperdibles oxidados por el tiempo que protegen el envoltorio del vestido de la niña muerta que la vieja, guardiana de la muerte, entrega como sudario a Mouchette. De esta manera, si el primer detonante del suicidio tiene lugar en el momento en que está descubre su propia mano, el segundo, y definitivo, se produce en el instante en que el tejido de muselina, gastado por el tiempo y tan frágil como una telaraña, según observa el descriptor, queda atrapado bajo el zueco de Mouchette, desgarrándose. Y así, el narrador se pregunta:

«¿Fue en aquel instante cuando Mouchette sufrió el segundo asalto de la fuerza oscura que acababa de despertarse en lo más profundo, en lo más secreto de su carne?» ${ }^{18}$.

Queda puesta de manifiesto, a través de esta breve prospección, la carga significante que adquiere el zapato en la escritura bernanosiana. Pero es en la primera novela del autor, Bajo el sol de Satanás, donde dicha carga alcanza su mayor relevancia, como elemento temático esencial que organiza la novela entera, tanto desde el punto de vista narrativo como simbólico, agrupando en torno suyo toda una constelación de imágenes.

Aludiendo a la función metonímica del zapato, antes observaba cómo este objeto resume la esencia del ser. Los zapatos, en efecto, definen al personaje ante los demás, produciéndose además curiosos cambios de perspectiva en función del elemento perceptor. De esta manera, el Marqués de Cadignan -auténtica ruina histórica- es calificado despectivamente por el padre de Mouchette como «marqués en chanclos», mientras que ésta lo ensueña como un héroe «con su traje de pana y sus gruesas botas, como un rey».

Bajo el sol de Satanás hubiera podido muy bien titularse Bajo los pies de Satanás, recogiendo una vieja imagen. «Satanás nos tiene bajos sus pies», exclama abatido el santo de Lumbres, y la suprema habilidad del Gram Impostor consiste, precisamente,

${ }^{15}$ La mano se mancha de sangre cuando Arsène se la lleva a la cabeza, tras la cafda sufrida debido $\mathrm{a}$ un repentino ataque epiléptico. Al paśrsela por la cabeza -lo que nos lleva a la asociación mano-memoria en función del fetichismo de la mano- el cazador entra en un estado de amnesia.

${ }^{16}$ Es especialmente significativo, como gesto anticipador del acto de violación, el hecho de que Arsène, al encontrarse con Mouchette, ha estado a punto de tropezar con ella, con sus gruesas botas rebosantes de virilidad.

${ }^{17}$ Nouvelle Histoire de Mouchette, p. 1316.

${ }^{18}$ Ibid., p. 1342. 
en colocar «sus pasos en los pasos». La metonimia del zapato conlleva, pues, una segunda metonimia, la del paso. Y, a este respecto, se puede observar en la novela -tan cargada de resonancias- cómo los pasos no sólo son sonoros, sino que lo son de manera distinta, como rasgo identificador de los personajes, desde los zuecos de la vieja ama, el eco de los pasos rápidos de Mouchette, el paso del padre Donissan, pesado y regular o pateo apremiante, a otro pateo, simbólico éste, pues está construido en el juego metafórico del lenguaje, mas no por ello menos sofocante: el del rebaño humano que atosiga implacable al párroco de Lumbres. Toda la novela es un caminar de múltiples pasos en el laberinto de la existencia.

En función de ello, el texto construye todo un juego en torno a la matización sonora del paso, creciente o decreciente, resonando en las losas de la iglesia o en la carretera, como existen cambios de ritmo en el caminar, metáfora de la existencia.

Ahora bien, dentro del juego de la sonoridad, hay pasos que escapan a ella, produciéndose toda una ambivalencia significante al respecto. De esta manera, el paso silencioso en principio es revelador de la mediocridad del ser. Pero también la ausencia de sonido es reveladora de la presencia de la muerte («sólo hay silencio absoluto al otro lado de la vida», comenta el autor ante la imagen del niño muerto) y, en la Nueva Historia, mientras los zuecos de Mouchette resuenan en los adoquines de la carretera, la guardiana de la muerte camina siempre silenciosa apoyándose en sus bastones.

En el extremo opuesto de la escala sonora, la exarcerbación del sonido, hasta llegar a la distorsión, puede ser igualmente significante de muerte: así, los clavos de los zapatones del padre Donissan resbalan y rechinan sobre el sílex a la entrada del cementerio en su paso hacia la iglesia, haciéndole casi caer. La distorsión sonora, en este caso, tiene un referente satánico muy preciso, y se asocia al tema de la falta, pues no en vano Donissan acaba de formular el voto sacrílego, el pacto con Satanás.

Veíamos antes, al aludira la Nueva Historia de Mouchette, cómo, en la impregnación temática que adquiere el zapato como metonimia del yo, se proyectaba la presencia de la muerte. La asociación entre zapato y muerte aparece ya en Bajo el sol de Satanás, si bien no de manera directa, sino a través de una nueva metonimia: la de la sangre. De esta manera, Mouchette, tras matar a su amante, lava sus zapatos manchados de sangre en la charca próxima, espacio, por otra parte, ensoñado por la niña como escenario de un posible suicidio. Un nuevo paralelismo se establece aquí entre la Mouchette de Bajo el sol y la heroína de la Nueva Historia, con una diferencia sustancial entre ambas, sin embargo, ya que, en el caso de la primera, sobre la charca pantanosa se proyecta toda la negrura de la conciencia, mientras que la segunda Mouchette se suicida en un agua cristalina.

Por otra parte, la asociación entre los zapatos y la sangre establece un paralelismo entre Mouchette y el padre Donissan -dos personajes en principio opuestos pero que se construyen el uno en función del otro, siendo los generadores directos del texto-. De esta manera, tras la escena de la flagelación, primera etapa de esa «tentación de la desesperación» que da su título a la primera parte de la novela, Donissan descubre sus zapatos en medio de un charco de sangre. 
«Pero, $i$ a qué soñar? En el instante decisivo, acepta el combate [...]. Ha nacido para la guerra; cada recodo en su camino estará marcado por un charco de sangre» 20 .

Tal es el destino que aguarda a Donissan, futuro santo de Lumbres. Un charco de sangre será la marca que establezca el primer recodo de un camino que no será sino una continua tentación de la desesperación.

Nacido para la guerra, el futuro santo de Lumbres se configura como un verdadero soldado-atleta. La tensión de la voluntad, que caracteriza a Donissan, se manifiesta en la eterna predisposición a la marcha de este incansable andarín. Ello, como luego veremos en la descripción que hace el autor, queda recogido en la posición vertical de un zapato que, in absentia, habla de su dueño con más elocuencia que cualquier lenguaje. Por otra parte, y a partir del zapato, surge una segunda observación que marca una profunda diferencia entre Mouchette y Donissan, ya que el eje que antes veíamos establecer entre ambos no es un eje de simetría, sino una polaridad de fuerzas. Así, Mouchette hace desaparecer los zapatos manchados con la sangre del crimen. Por el contrario, los zapatones de Donissan siempre están ahí, desde el principio hasta el final de la novela, dando testimonio de una lucha perpetua. Ello es significante de una postura ante la existencia radicalmente distinta en uno y otro personaje: Mientras el planteamiento de Mouchette es de carácter esencialista, Donissan plantea su existencia en torno al estar ${ }^{21}$, como presencia inalterable frente al mal. La incineración de los zapatos de Mouchette constituye entonces un gesto simbólico que metaforiza un devenir existencial en una dinámica que culminará en negación ontológica a partir, precisamente, del crimen.

Si, como veíamos antes, el paso, el caminar, se inscribe en el espectro semántico del zapato, la espacialización del gesto da lugar a la imagen de la carretera, verdadero eje temático en torno al cual se articula la dinámica del texto. Satanás se define como «la ruta sin salida» (en francés «ruta» y «carretera» concurren en un mismo lexema), y veíamos antes cómo su mentira es la del impostor que pisa exactamente en las mismas huellas ${ }^{22}$.

La carretera es en sí misma una imagen espacial ambivalente, pues en principio es llamada hacia el descubrimiento y la esperanza. La mejor descripción la encontramos en Monsieur Ouine:

${ }^{19} \mathrm{La}$ Mouchette a la que me refiero aquí es el primer personaje que Bernanos crea con este nombre, en Sous le soleil de Satan. Mouchette era un principio un nombre provisional para el personaje de la Nouvelle Histoire, pero su creador es incapaz de llamarla de otra forma. En realidad, a pesar de tratarse de dos heroínas completamente distintas, incluso opuestas, hay un sustrato común del que las dos derivan, como de una misma sustancia.

${ }^{20} \mathrm{G}$. Bernanos, Oeuvres romanesques (cit.), Sous le soleil de Satan, p. 147.

${ }^{21}$ «Soy yo", son precisamente las palabras que Mouchette pronuncia al irrumpir en casa de su amante en la noche de su fracasada liberación existencial. Por el contrario, «estoy aquí», son las palabras que definen a Donissan, y aparecen en su boca de manera paralela al iniciarse tanto la primera como la segunda parte de la novela.

22 «Yo soy la puerta cerrada para siempre, la ruta sin salida, la mentira y la perdición» es la autodefinición de Satanás. Oeuvres romanesques, Journal d'un curé de campagne, p. 1046. 
«iHermosa carretera! ¡Querida carretera! ¡Vertiginosa amiga, promesa inmensa! El hombre que la ha hecho con sus manos pulgada a pulgada, socavándola hasta el corazón, hasta su corazón de piedra, y luego la ha pulido, acariciado, ya no la reconoce, cree en ella. [...] Quien no ha visto la carretera al alba, entre sus dos filas de árboles, fresca, viva, no sabe lo que es la esperanza» ${ }^{23}$.

La carga emblemática que dicha imagen adquiere en Bernanos, perpetuo itinerante, es tal, que el planteamiento del texto citado constituye, en realidad, un metadiscurso de la escritura.

En torno a la carretera y sus imágenes asociadas, senda o camino, se genera una itinerancia donde el componente físico pasa a ser significante de una realidad existencial y espiritual, como búsqueda y perdición en una estructura circular en la que se ven inmersos todos los personajes. Dicha estructura se tematiza en lo que podemos denominar El viaje de Colón, superponiéndose entonces un imaginario de tipo marino.

«En el jardín de tejos recortados, bajo la desnuda veranda, que huele a almáciga quemada, dice el autor refiriéndose a Mouchette, se cansó ella de esperar no se sabe qué, que nunca viene, la niña ambiciosa. De allí partió, y se fue más lejos que a las Indias... Por suerte para Cristóbal Colón, la tierra es redonda; la carabela legendaria, no bien hubo hundido su estrave, cuando estaba ya en la ruta de vuelta...» ${ }^{24}$.

El viaje de Colón, a través de una ensoñación paradójica, no conduce a descubrimiento alguno, sino a la exacta constatación de la redondez de la tierra, a la vuelta exacta al punto de partida. El viaje de Colón no es un camino de ida, sino de vuelta. De esta manera, la dinámica existencial de todos y cada uno de los personajes (lo cual es extensible, por otro lado, al resto de la producción bernanosiana) se genera, sobre el tema central de la itinerancia, como una dinámica circular. Así, en el episodio del encuentro con Satanás, la carretera lleva a Donissan a volver una y otra vez al mismo punto. La propia estructura del sol de Satanás es circular en este sentido, a partir del empleo de la redundancia especular y una "puesta en abismo» constante desde el principio al fin de la novela, en un continuo rebotar de unos elementos sobre otros.

El empleo del imaginario marino como semántica de la muerte nos da finalmente la clave del verdadero punto de llegada del viaje de Colón. Una de las imágenes centrales del texto desde el punto de vista simbólico la constituye precisamente la focalización sobre el niño muerto, «cuyo catre de hierro, señala el autor, se asemeja a un fantástico navío, que ha echado el ancla para siempre». El punto de llegada no es otro que la muerte, el anclaje para siempre.

Pero de tantos pies como transitan por el texto, sólo unos zapatos son descritos. Así, mientras uno de los personajes de la novela, el escritor Saint-Marin, inspecciona curioso la habitación del santo de Lumbres, su mirada se fija y detiene en los zapatones del sacerdote ausente:

\footnotetext{
${ }^{23}$ Monsieur Ouine, p. 1408.

${ }^{24}$ Oeuvres romanesques, Sous le soleil de Satan, p. 68.
} 
«Miraba -comenta el narrador- dos zapatones boquiabiertos, descoloridos por el tiempo, el uno de pie, curiosamente plantado, el otro sobre el suelo, enseñando sus clavos oxidados, su cuero combado, las suelas levantadas, dos pobres viejos zapatos, más miserables que si fueran hombres» 25 .

En tomo a ellos, que llevan escrita la historia de Donissan, se construye la novela entera. Y precisamente la descripción no aparecerá hasta el final, cuando esta historia está ya consumada. Zapatos toscos, duros e infatigables como el santo de Lumbres, recogiendo la dimensión grotesca y noble del personaje. Zapatos de campesino en perpetua predisposición a la marcha, después de haber caminado tanto («qué ridícula y maravillosa imagen», exclamará Saint-Marin al contemplarlos). La visión de los zapatones hará pensar inmediatamente al escritor «en la fuga circular de toda vida humana, en el camino recorrido en vano, en el supremo paso en falso».

En función de todo ello es como adquiere su auténtico sentido la imagen última del texto, en la que la mirada recorre lentamente los zapatones del santo en su confesonario-idénticos, precisa el descriptor, a los que había arriba-con un tacón puesto en el umbral, dispuesto a la lucha aún después de la muerte, «como un centinela muerto de una bala en su garita, a quemarropa». En la constelación semántica de la guerra, el camino de regreso por el que ha vuelto el santo de Lumbres al final de la novela es comparado al caminar sin sentido de los ejércitos vencidos. Conviene señalar aquí que la Guerra Mundial, que para Bernanos pervierte la palabra, es el referente anecdótico directo generador de la novela, como lo es de toda la producción de su escritura ${ }^{26}$. Del zapato a la carretera, de la metonimia corporal a la memoria y de ésta a la Historia, la brecha final es desgarro del yo sobre el que finalmente revierte, a partir de una interiorización existencial.

${ }^{25}$ Ibid., p. 287.

${ }^{26} \mathrm{Cf}$. mi introducción a Bajo el sol de Satanás, aparecida recientemente en Cátedra (colección «Letras Universales»). La Guerra, generador de escritura, no genera materia narrativa, sino metafórica. 